\title{
Fibromyalgia syndrome improved using a mostly raw vegetarian diet: An observational study Michael S Donaldson ${ }^{* 1}$, Neal Speight ${ }^{2}$ and Stephen Loomis3
}

Address: ${ }^{1}$ Hallelujah Acres Foundation, Shelby, NC USA, ${ }^{2}$ Center for Wellness, Charlotte, NC USA and 3 Cleveland Physical Therapy Associates, Shelby, NC USA

E-mail: Michael S Donaldson* - michael@hacres.com; Neal Speight - nspeight@aol.com; Stephen Loomis - mcsl1@yahoo.com

*Corresponding author

Published: 26 September 2001

BMC Complementary and Alternative Medicine 200I, 1:7
Received: 20 June 2001

Accepted: 26 September 2001

This article is available from: http://www.biomedcentral.com/1472-6882/1/7

(c) 200 I Donaldson et al; licensee BioMed Central Ltd. Verbatim copying and redistribution of this article are permitted in any medium for any noncommercial purpose, provided this notice is preserved along with the article's original URL. For commercial use, contact info@biomedcentral.com

\begin{abstract}
Background: Fibromyalgia engulfs patients in a downward, reinforcing cycle of unrestorative sleep, chronic pain, fatigue, inactivity, and depression. In this study we tested whether a mostly raw vegetarian diet would significantly improve fibromyalgia symptoms.

Methods: Thirty people participated in a dietary intervention using a mostly raw, pure vegetarian diet. The diet consisted of raw fruits, salads, carrot juice, tubers, grain products, nuts, seeds, and a dehydrated barley grass juice product. Outcomes measured were dietary intake, the fibromyalgia impact questionnaire (FIQ), SF-36 health survey, a quality of life survey (QOLS), and physical performance measurements.
\end{abstract}

Results: Twenty-six subjects returned dietary surveys at 2 months; 20 subjects returned surveys at the beginning, end, and at either 2 or 4 months of intervention; 3 subjects were lost to followup. The mean FIQ score $(n=20)$ was reduced $46 \%$ from $5 I$ to 28 . Seven of the 8 SF- 36 subscales, bodily pain being the exception, showed significant improvement $(n=20$, all $P$ for trend $<0.01)$. The QOLS, scaled from 0 to 7 , rose from 3.9 initially to 4.9 at 7 months $(n=20, P$ for trend $0.000001)$. Significant improvements $(n=18, P<0.03$, paired t-test) were seen in shoulder pain at rest and after motion, abduction range of motion of shoulder, flexibility, chair test, and 6-minute walk. 19 of 30 subjects were classified as responders, with significant improvement on all measured outcomes, compared to no improvement among non-responders. At 7 months responders' SF-36 scores for all scales except bodily pain were no longer statistically different from norms for women ages $45-54$.

Conclusion: This dietary intervention shows that many fibromyalgia subjects can be helped by a mostly raw vegetarian diet.

\section{Background}

The fibromyalgia syndrome (FMS) is characterized by wide spread pain in the body, associated with particular tender points $[1,2]$. It is often accompanied by unrestorative sleep patterns, fatigue, headaches, irritable bowel and bladder syndrome, morning stiffness, paresthesias, anxiety, and depression $[2,3]$. The prevalence rate is about $2 \%$ in the general population, $3.9 \%$ of women ages $20-40$ and $5.8 \%$ of women ages $40-60$ [4], and as high as $8 \%$ in women ages $55-64$ [5]. FMS is more prevalent 
in women than men, in about a 3:1 ratio [5]. People who suffer from FMS have a disability index comparable to that of patients with rheumatoid arthritis [6] while disease severity was worse than Sjogren's syndrome [7]. The natural course of FMS may include some symptomatic relief [8], but many symptoms remain essentially unchanged after 7 years of follow up [9].

Treatments for FMS include medications (amitriptyline and fluoxetine most common), nutritional supplements (malic acid, s-adenosyl methionine, 5-hydroxytryptophan), and physical therapies (cardiovascular training, stretching, electroacupuncture), and cognitive-behavior therapy [reviewed in [10-12]]. FMS patients frequently use alternative therapies, indicating dissatisfaction, or ineffectiveness of traditional medical therapy [13].

FMS engulfs patients in a downward spiral of unrestorative sleep, chronic pain, fatigue, inactivity, and depression. Each symptom reinforces the others, making it difficult to break out of the cycle. A 3-week vegetarian diet improved subjective well being in FMS patients, along with significant reductions in serum peroxides, plasma fibrinogen, apolipoproteins $\mathrm{A}$ and $\mathrm{B}$, and serum total cholesterol [14]. A "living-foods" vegan diet was used in a 3-month non-randomized controlled study of FMS subjects [15]. In the intervention group there were significant improvements in pain scores, quality of sleep, morning stiffness, health assessment questionnaire scores, and general health questionnaire. These studies, along with anecdotal evidence that we have gathered, indicate that a mostly raw food vegetarian diet is helpful in breaking the cycle of suffering of FMS patients.

In this study we utilized a pure vegetarian diet composed mostly of common fruits, vegetables, nuts, tubers, carrot juice, and dehydrated barley grass juice while tracking participants' FMS status during a 7-month period of time.

\section{Methods}

\section{Subjects}

Subjects were recruited from a local fibromyalgia support group, by notice of the study in a bi-yearly newsletter, and by word of mouth. An informed consent document explaining the study and the risks and benefits of participation was given to each potential subject. Written consent was obtained from subjects before participation. The study was conducted in accord with the ethical standards of the Helsinki Declaration of 1975 as revised in 1983 .

Subjects were required to have a previous diagnosis of FMS by a rheumatologist, using the American College of Rheumatology criteria of at least 11 of 18 tender points being painful upon palpation. Subjects underwent a physical examination upon entering the study, including the tender point survey.

Subjects were encouraged to continue with any medication for sleep or pain. It was believed that this would allow the best comparison between initial and final conditions, with as few variables changing as possible. Subjects and their prescribing physicians made all medication decisions. The investigators in this study had no control of medication usage.

\section{Diet implementation}

Subjects were supplied with books published by Hallelujah Acres, Inc. (God's Way to Ultimate Health, Recipes for Life...from God's Garden, 21 Days to health the Hallelujah diet way) and informational pamphlets. Instructions were given on what foods to eat (fresh fruits, salads, raw vegetables, carrot juice, nuts, seeds, whole grain products, tubers, flax seed oil, extra virgin olive oil) what foods to avoid (alcohol, caffeine, foods containing refined sugar, corn syrup, refined and/or hydrogenated oil, refined flour, dairy, eggs, and all meat) and how to prepare freshly extracted carrot juice with the supplied Champion juicer (Plastaket Mfg. Co. Inc., Lodi, CA). Subjects were given a 2-month supply of dehydrated barley grass juice powder (Barleygreen) and a blend of laxative herbs and psyllium seed (Herbal Fiberblend) (AIM International, Nampa, ID), with instruction to ask for more when this supply was finished. Subjects were encouraged to attend a live motivational presentation of the basis of the Hallelujah Diet to reorient their thinking about food and health. A video was available for those subjects that did not attend the presentation. No regular support meetings were scheduled for motivational encouragement after this initial presentation, as this might make the results less applicable to the general population.

\section{Main outcome measures}

Physical performance measures, as detailed by Mannerkorpi, et al. [16], were collected at the beginning and end of the study. 12 measures were used. These were shoulder pain at rest, range of active motion abduction and flexion, shoulder pain on motion, hand to neck, hand to scapula, isometric shoulder endurance, neck rotation, hand grip strength, flexibility of the low back and hamstrings using the sit-and-reach method, chair test (number of times a subject could stand up in a minute), and a six-minute walk. All of these measures were taken by the same physical therapist (SL). Along with these objective tests, subjects were asked to report their health status using the Fibromyalgia Impact Questionnaire [17], the SF-36 short form health survey [18], and a Quality of Life Survey [19]. The SF-36 has been widely used to record how a person perceives his or her own health sta- 
tus. The quality of life survey queries the subject about 16 different aspects of life with a scale from o to 7 for each question. These questionnaires were self-administered at $0,2,4$, and 7 months.

A food frequency questionnaire (FFQ), designed to include commonly eaten foods while following the Hallelujah Diet, was also self-administered at 2, 4, and 7 months. The FFQ administered at 2 months was analyzed using The Food Processor, version 7.40 (ESHA Research, Eugene, OR).

\section{Statistics}

The FIQ, QOL, and SF-36 surveys were analyzed by repeated measures analysis of variance. Differences between time points were calculated using the Bonferroni comparison. A subgroup of 20 of the participants was used that reported in the beginning, end, and either 2 or 4 months into the trial. The physical performance measures were analyzed by the student's paired t-test. 18 subjects gave initial and final physical performance measures. A significance level less than 0.05 was considered statistically significant.

Responders and non-responders were initially distinguished using the FIQ score. If a subject reported at least a 10-point improvement in their initial and final FIQ score, then that subject was classified as a responder. A 10-point improvement in the FIQ correlated with statistically significant improvements in measures of physical performance, QOLS scores, and SF-36 scores.

\section{Results}

Subjects

30 subjects participated in this study, 28 female, 2 male. All subjects had been previously diagnosed with fibromyalgia by a rheumatologist, but not all subjects currently had 11 or more positive tender points. All subjects had symptoms which they attributed to FMS.

Compliance of subjects was monitored by self-reported food intakes on a food frequency questionnaire, and by requests for more dehydrated barley grass juice. Approximately a two-month supply was initially given to each subject, with instructions to call and ask for more when their supply ran out.

20 subjects ( 15 of whom are classified as responders) returned surveys at the beginning, end, and either 2 or 4 months. Detailed results for the self-reported questionnaires (FIQ, SF-36, QOLS) here are reported for this subgroup. Response (responder or non-responder) to the dietary intervention is reported based on all 30 subjects according to the intention to treat principle. Analysis shows there were no significant differences in gathered data between the whole group and this sub-group.

Table I: Nutrient Intake of Subjects. N = 26.

\begin{tabular}{lc}
\hline MACRONUTRIENTS \\
\hline \\
Calories \\
Protein, g & $1700 \pm 490$ \\
Carbohydrate, g & $48 \pm 15$ \\
Fiber, g & $299 \pm 83$ \\
Fat-Total, g & $45 \pm 14$ \\
Cholesterol, mg & $50 \pm 24$ \\
\end{tabular}

VITAMINS

$\begin{array}{lc}\text { Vitamin A, RE } & 10,300 \pm 4,200 \\ \text { Thiamin, mg } & 2.1 \pm 0.5 \\ \text { Riboflavin, mg } & 1.7 \pm 0.4 \\ \text { Niacin, mg } & 16.0 \pm 4.7 \\ \text { Vitamin B6, mg } & 3.6 \pm 1.0 \\ \text { Vitamin B I2, } \mathrm{gg} & 0.6 \pm 0.7 \\ \text { Vitamin C, mg } & 570 \pm 210 \\ \text { Vitamin D, } \mu g & 0.46 \pm 0.47 \\ \text { Vitamin E, } \alpha-\mathrm{TE} & 18.1 \pm 7.0 \\ \text { Folate, } \mathrm{mg} & 550 \pm 200\end{array}$

MINERALS

$\begin{array}{lc}\text { Calcium, mg } & 720 \pm 220 \\ \text { Copper, mg } & 2.4 \pm 0.7 \\ \text { Iron, mg } & 15.8 \pm 4.2 \\ \text { Magnesium, mg } & 460 \pm 140 \\ \text { Phosphorus, mg } & 1090 \pm 300 \\ \text { Potassium, mg } & 6400 \pm 1400 \\ \text { Sodium, mg } & 1800 \pm 930 \\ \text { Zinc, mg } & 8.3 \pm 2.3\end{array}$

\section{Dietary intake}

Food frequency questionnaires were collected from 26 participants. Nutrient intakes, based on the FFQ administered at 2 months, are reported in Table 1 . Diet percentages, on an energy basis, were 24 percent fat, 65 percent carbohydrate, and 11 percent protein. Participants reported drinking 2-4240 $\mathrm{ml}$ servings of carrot juice daily, so that the mean intake of beta-carotene was $52 \mathrm{mg} /$ day. Several participants reported less consumption of carrot juice at 7 months than at 2 months. The dehydrated barley grass juice was consumed by all but 2 subjects who reported immediate nausea upon consumption of the 
powder. Flax seed oil was consumed by 23 of 26 participants so that the mean intake of n-3 fatty acids was about $6 \mathrm{~g} /$ day. Fresh fruit and salads, based mostly on leaf lettuce and dark leafy greens rather than head lettuce, were consumed daily. The high intakes of fruits and vegetables resulted in high intakes of fiber, vitamin $\mathrm{C}$, folate, potassium, and magnesium. Animal product consumption was very low, especially intakes of meat, poultry, and fish. Intakes were mainly from once weekly to none, resulting in low intakes of fat, cholesterol, vitamins B12 and D, and zinc. Soft drink intake was reported in 11 subjects, demonstrating willingness to report truthfully. Only 3 subjects reported consuming more than a $340 \mathrm{ml}$ serving per week.

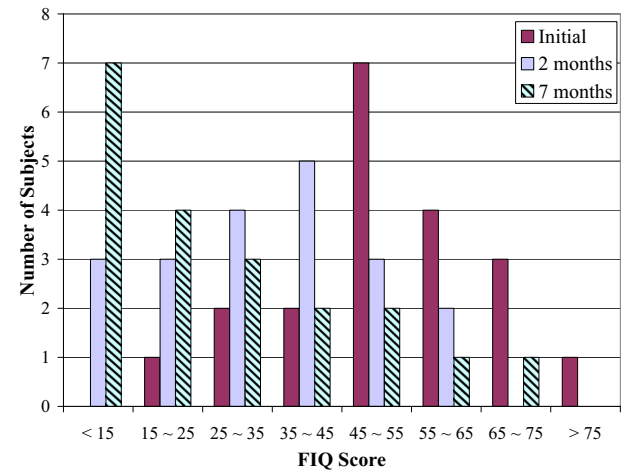

Figure I

Histogram of total fibromyalgia impact questionnaire (FIQ) score. The number of subjects ( $n=20$ at each time point) with scores in each range is shown for 0,2 , and 7 months of dietary intervention. Increasing score denotes a greater negative impact of FMS on the subject.

\section{Physical performance}

Eighteen subjects were followed up after completion of the study (see Table 2). Results are only reported for these 18 subjects, 13 of whom were classified as responders, Initial values were very similar to values reported by Mannerkorpi et al. [16]. Significant improvements ( $\mathrm{P}<$ 0.03 , paired t-test) in these 18 subjects were seen in shoulder pain at rest and after motion, abduct range of motion of shoulder, flexibility (sit and reach), chair test, and 6-minute walk. Neck rotation (left only) was also significantly improved. Hand grip strength decreased significantly in right hand and decreased to a lesser extent in the left hand. Isometric shoulder endurance showed no change.

\section{FIQ}

The FIQ is a survey designed specifically to measure the impact of fibromyalgia on a person's life. After two months the mean FIQ score had fallen from 51 points to 34 points and decreased further to 28 points at seven months, ( $\mathrm{n}=20$ at each time point). This is a $33 \% \mathrm{im}-$ provement after 2 months, and a $46 \%$ improvement after 7 months. The histogram in Figure 1 of the FIQ score shows a decrease in the scores as the trial progressed.

There was a significant trend (all $\mathrm{P}<0.05$ ) for improvement in all scales (see Table 3). There were significant improvements $(\mathrm{P}<0.05$ with Bonferroni correction) in all of the FIQ sub-scales from 0-7 months, and almost all of the sub-scales from 0-2 months ("work missed" and "days feeling good" being the exceptions) (see Table 3).

\section{QOL}

Quality of life improved during this 7-month trial, with the composite score rising from an initial 3.9 to 4.7 at 2 months and 4.9 at 7 months $(\mathrm{n}=20$ each time point, $\mathrm{P}$ for trend $<1 \mathrm{E}-6$ ), on a scale of 0 to 7 , with 7 being a delighted quality of life. There were significant differences between initial and 2 month scores, and initial and 7 month scores, but not between 2 and 7 month scores (P $<0.05$ with Bonferroni correction). The biggest impact was seen in active recreation, health, socializing, and participation in organizations.

\section{SF-36}

The SF-36 health survey breaks down health into 8 subheadings. These areas are physical functioning, role physical, bodily pain, general health, vitality, social functioning, role emotional, and mental health (see Table 4). 7 of these 8 areas, bodily pain being the exception, showed significant improvement $(n=20$ each time point, all $\mathrm{P}$ for trend $<0.01)$. There were significant differences for these 7 headings between initial and 2 month scores, except for general health, and also between initial and 7 month scores, but not between 2 and 7 month scores $(\mathrm{P}<0.05$ with Bonferroni correction).

Norms for the general population's responses to the SF36 questionnaire have been published [20]. Initially, the mean score for all of the SF-36 scales were significantly lower than the norms for women ages 45-54. After 7 months of dietary intervention 4 scales were no longer significantly different from the norms, showing marked improvement (general health, vitality, role emotional, mental health) (see Table 4).

\section{Responders versus non-responders}

A 10-point improvement in the FIQ score was used to distinguish responders from non-responders. 19 subjects were classified as responders, 8 as non-responders, and 3 individuals did not follow through on initial evaluations. Mean FIQ score improvement for responders was 30 points, with a range from 11 to 62 points. Mean FIQ 
Table 2: Physical Evaluation of Subjects.

\begin{tabular}{|c|c|c|c|}
\hline & Initial, $n=18$ & $\begin{array}{l}7 \text { Months, } \\
\mathrm{n}=18\end{array}$ & $\begin{array}{l}P \text { value, } \\
\text { paired }\end{array}$ \\
\hline & Mean \pm SD & Mean \pm SD & t-test \\
\hline I. Shoulder pain at rest (R) (scale I-10, 10 worse) & $3.9 \pm 2.4$ & $1.4 \pm 2.0$ & 0.0010 \\
\hline 2. Shoulder pain at rest (L) (scale I-10, 10 worse) & $3.4 \pm 2.5$ & $1.3 \pm 1.9$ & 0.0011 \\
\hline 3. Range of active motion of shoulder, flex (R) (degrees) & $153 \pm 18$ & $161 \pm 14$ & 0.086 \\
\hline 4. Range of active motion of shoulder, flex (L) (degrees) & $150 \pm 2 \mid$ & $159 \pm 19$ & 0.114 \\
\hline \multicolumn{4}{|l|}{ 5. Range of active motion of shoulder, abduct (R) } \\
\hline (degrees) & $137 \pm 24$ & $157 \pm 19$ & 0.0020 \\
\hline \multicolumn{4}{|l|}{ 6. Range of active motion of shoulder, abduct (L) } \\
\hline (degrees) & $139 \pm 28$ & $155 \pm 28$ & 0.0097 \\
\hline 7. Shoulder pain on motion (R) (scale I-10, 10 worse) & $4.1 \pm 2.5$ & $2.0 \pm 2.7$ & 0.0071 \\
\hline 8. Shoulder pain on motion (L) (scale I-10, 10 worse) & $3.7 \pm 2.9$ & $1.4 \pm 1.9$ & 0.0021 \\
\hline 9. Hand-to-neck (R) $(0-4)$ & $0.22 \pm 0.55$ & $0.06 \pm 0.24$ & 0.27 \\
\hline 10. Hand-to-neck (L) $(0-4)$ & $0.22 \pm 0.55$ & $0.11 \pm 0.32$ & 0.50 \\
\hline II. Hand-to-scapula (R) $(0-4)$ & $0.50 \pm 0.62$ & $0.11 \pm 0.32$ & 0.0147 \\
\hline 12. Hand-to-scapula (L) $(0-4)$ & $0.44 \pm 0.62$ & $0.28 \pm 0.75$ & 0.19 \\
\hline 13. Isometric shoulder endurance (R) (sec) & $69 \pm 47$ & $77 \pm 50$ & 0.36 \\
\hline I4. Isometric shoulder endurance (L) (sec) & $73 \pm 52$ & $80 \pm 57$ & 0.52 \\
\hline 15. Neck rotation (R) (degrees) & $66 \pm 7$ & $70 \pm 11$ & 0.13 \\
\hline 16. Neck rotation (L) (degrees) & $56 \pm 12$ & $68 \pm 12$ & 0.00003 \\
\hline I7. Flexibility (sit-and-reach) (cm) & $-10.5 \pm 9.4$ & $-4.4 \pm 6.5$ & 0.0038 \\
\hline 18. Chair test (times/minute) & $16.4 \pm 6.8$ & $19.1 \pm 8.1$ & 0.028 \\
\hline 19. Hand grip strength (R) & $39 \pm 17$ & $30 \pm 15$ & 0.017 \\
\hline 20. Hand grip strength (L) & $36 \pm 17$ & $30 \pm 14$ & 0.078 \\
\hline 21. Six-minute walk (m) & $465 \pm 98$ & $514 \pm 112$ & 0.012 \\
\hline
\end{tabular}

Table 3: Fibromyalgia Impact Questionnaire Results. N = 20 at each time point.

\begin{tabular}{|c|c|c|c|c|}
\hline & $\begin{array}{l}\text { Initial } \\
\text { Mean } \pm \text { SD }\end{array}$ & $\begin{array}{l}2 \text { months } \\
\text { Mean } \pm S D\end{array}$ & $\begin{array}{l}7 \text { months } \\
\text { Mean } \pm \text { SD }\end{array}$ & $\begin{array}{l}P \text { for } \\
\text { trend }\end{array}$ \\
\hline FIQ score & $51.4 \pm 14.2^{\mathrm{a}}$ & $33.6 \pm 15.6^{b}$ & $27.6 \pm 19.0^{b}$ & $2.5 \mathrm{E}-07$ \\
\hline Physical impairment & $4.8 \pm 2.3^{a}$ & $3.6 \pm 2.5^{b}$ & $2.7 \pm 2.6^{b}$ & $3.5 \mathrm{E}-04$ \\
\hline Feel Good & $6.7 \pm 3.1 \mathrm{a}$ & $4.6 \pm 3.5^{\mathrm{a}}$ & $3.6 \pm 3.4 b$ & $1.8 \mathrm{E}-03$ \\
\hline Work missed & $2.6 \pm 3.0^{a}$ & $1.8 \pm 2.8^{a}$ & $0.6 \pm 1.3^{b}$ & 2.7E-02 \\
\hline Do Job & $6.3 \pm 2.0^{a}$ & $4.1 \pm 2.3^{b}$ & $3.3 \pm 2.7 \mathrm{~b}$ & $2.6 \mathrm{E}-06$ \\
\hline Pain & $6.6 \pm 1.9 \mathrm{a}$ & $4.5 \pm 1.9 \mathrm{~b}$ & $3.6 \pm 2.5^{b}$ & 2.7E-06 \\
\hline Fatigue & $7.8 \pm 2.0^{a}$ & $5.1 \pm 2.2^{b}$ & $4.4 \pm 2.8^{b}$ & $7.8 \mathrm{E}-06$ \\
\hline Rested & $7.8 \pm 1.8^{a}$ & $4.7 \pm 2.6^{b}$ & $4.1 \pm 2.9^{b}$ & $1.4 \mathrm{E}-06$ \\
\hline Stiffness & $7.1 \pm 2.1^{a}$ & $4.8 \pm 2.2^{b}$ & $3.8 \pm 2.3^{b}$ & I.4E-07 \\
\hline Anxiety & $5.7 \pm 2.7^{a}$ & $3.2 \pm 2.0^{\mathrm{b}}$ & $3.0 \pm 2.3^{b}$ & $6.5 \mathrm{E}-05$ \\
\hline Depression & $5.0 \pm 3.0^{a}$ & $3.1 \pm 2.2^{b}$ & $2.4 \pm 2.5^{b}$ & I.6E-04 \\
\hline
\end{tabular}

Numbers with different superscripts are statistically different $(P<0.05$ with Bonferroni adjustment).

score decreased by 3.6 points for non-responders, with a range from 3.5 to -14.6 points. The responders' SF-36 scores at 7 months for all scales except bodily pain were no longer statistically different from norms for women ages $45-54$. Responders to the dietary intervention also had significant improvements in physical performance and QOL scores (data not shown), while non-responders had no significant change in their fibromyalgia status. 
Table 4: SF-36 Results. Norm data is for women aged 45-54 [20]. $\mathrm{N}=20$ at each time point.

\begin{tabular}{|c|c|c|c|c|c|}
\hline SF-36 Scale & $\begin{array}{l}\text { Norm } \\
\text { Mean } \pm \text { SD }\end{array}$ & $\begin{array}{l}\text { Initial } \\
\text { Mean } \pm \text { SD }\end{array}$ & $\begin{array}{l}2 \text { months } \\
\text { Mean } \pm \text { SD }\end{array}$ & $\begin{array}{l}7 \text { months } \\
\text { Mean } \pm \text { SD }\end{array}$ & $\begin{array}{l}P \text { for } \\
\text { trend }\end{array}$ \\
\hline Physical Functioning & $82.9 \pm 21.7^{a}$ & $36.3 \pm 24.3^{b}$ & $55.0 \pm 23.4^{c}$ & $60.3 \pm 26.7^{c}$ & I.7E-06 \\
\hline Role Physical & $79.9 \pm 35.4^{a}$ & $6.3 \pm 11.1^{b}$ & $31.3 \pm 42.0^{c}$ & $36.3 \pm 41.7 c$ & 0.0074 \\
\hline Bodily Pain & $72.1 \pm 23.3^{a}$ & $32.6 \pm 20.2^{b}$ & $40.1 \pm 23.2^{c}$ & $48.5 \pm 28.8^{b}$ & 0.071 \\
\hline General Health & $70.5 \pm 20.6^{a}$ & $44.1 \pm 21.6^{b}$ & $\begin{array}{l}52.0 \pm \\
23.3^{b, c}\end{array}$ & $61.2 \pm 24.8^{\mathrm{a}, \mathrm{c}}$ & 2.3E-05 \\
\hline Vitality & $60.6 \pm 21.3^{a}$ & $18.0 \pm 14.4^{b}$ & $41.8 \pm 27.4^{c}$ & $48.0 \pm 28.9 \mathrm{a}, \mathrm{c}$ & $2.4 \mathrm{E}-05$ \\
\hline Social Functioning & $82.7 \pm 20.8^{a}$ & $40.0 \pm 26.5^{b}$ & $60.6 \pm 22.3^{c}$ & $66.3 \pm 25.7 c$ & $6.4 \mathrm{E}-05$ \\
\hline Role Emotional & $81.9 \pm 33.3^{a}$ & $25.0 \pm 26.5^{b}$ & $61.7 \pm 22.3^{a}$ & $75.0 \pm 25.7^{\mathrm{a}}$ & $1.6 \mathrm{E}-04$ \\
\hline Mental Health & $74.4 \pm 18.1^{a}$ & $57.2 \pm 23.1^{b}$ & $73.4 \pm 18.3^{a}$ & $77.0 \pm 15.3^{\mathrm{a}}$ & 4.7E-04 \\
\hline
\end{tabular}

Numbers with different superscripts are statistically different $(P<0.05$ with Bonferroni adjustment).

\section{Discussion}

The connection between dietary and lifestyle habits with chronic diseases has become increasingly strong in the past several years. Most of the research has been towards the prevention of chronic disease rather than toward its treatment.

The natural course of fibromyalgia shows that symptoms are generally the same over at least 7 years [3]. A stable, sharp reduction in symptoms in seven months, as we have reported here, is a definite alteration of the natural history of fibromyalgia.

Group treatment of fibromyalgia patients using a multifaceted approach resulted in a $25 \%$ improvement in overall FIQ score and a $5.2 \mathrm{~cm}$ increase in sit and reach flexibility [21]. This study resulted in even greater improvements with a $46 \%$ improvement in overall FIQ score and a $6.1 \mathrm{~cm}$ increase in sit-and-reach flexibility. A six-week exercise and education program produced a total drop in 8 FIQ subscales of 2.4 points [22]; these same subscales in this study decreased by 23.9 points after the dietary intervention reported here. This comparison shows that education and exercise are not as an effective intervention as this dietary intervention.

As mentioned, vegetarian dietary intervention of fibromyalgia has been tested by two investigators. In a small study of 10 patients, Hostmark et al [14] found a 3-week vegetarian diet produced an improvement in subjective well-being. Increase in well-being, as seen in the improvement in quality of life, FIQ, and SF-36 scores, was also seen in our study. In a recent study Kaartinen et al [15] used a strict "living-foods" pure vegetarian diet in 3month non-randomized, controlled study of FMS. Investigators saw significant improvements in pain scores and significantly less morning stiffness, similar to our re- sults. Apparently the diet was difficult to implement and no subjects continued with the "living-foods" diet. Symptoms returned upon reverting back to a more standard diet, showing even more clearly the association of diet and FMS. Maintenance of diets requiring more food preparation time and uncommon foods is difficult. Since the diet used here is mainly based on common foods the long-term adherence to the program is likely to be higher. Subjects learned which foods caused them the most symptoms so that they avoided these foods on a longterm basis.

Initial scores using the SF-36 health survey, compared to population norms, were very similar to those reported elsewhere [7]. This indicates that our fibromyalgia subjects were very similar to other surveyed groups in terms of their health status. Initial FIQ scores are also in line with other studies [21]. After 7 months, the 19 subjects that responded to the diet were no longer statistically different from the general population of women aged 4554 , except for bodily pain. This indicates a remarkable recovery of function in a short period of time.

Self-reported pain was significantly reduced as measured by the FIQ and by the physical performance measurements, but not as measured by the SF-36 questionnaire. Both the FIQ and physical performance measure used a visual analog scale from o-10 to measure pain, whereas the SF- 36 only used 2 questions with a total range of 10 points to measure bodily pain. This may have made the SF-36 a less sensitive measure of bodily pain than the other two measures.

It was unclear whether or not closer adherence to the diet by the non-responders would have resulted in better success. Without rapid improvements a few subjects lost motivation and adhered less to the diet, while others saw 
positive results within a couple of weeks, thus encouraging them to continue faithfully. The basis for not responding to the diet may have been physiological rather than motivational. Further research will help answer this question.

What caused the significant improvements seen in this intervention study? There is likely a synergy of both physiological and psychological factors. The change in diet gave the subjects motivation to take control of their symptoms, to overcome their disabilities and inactivity. People that believed that a change in their diet would improve their symptoms were attracted to this study. The effect of expecting a positive result was not measured, but it certainly was beneficial to the subjects.

Some aspects of the new diet also improve fatigue and sleep patterns, so that overwhelming fatigue did not squelch subjects' newfound motivation. Subjects could begin an upward cycle out of their FMS symptoms, rather continuing the downward trend toward further disability, chronic pain, and depression.

Intakes of fats, protein, fiber, several vitamins, including the antioxidants vitamin $\mathrm{C}$, vitamin $\mathrm{E}$, and beta-carotene, and minerals (especially magnesium, potassium, and zinc) are significantly different from the general population's dietary intake (see Table 1), so it is difficult to single out which factors were most important in producing the dramatic improvements seen in this study. The improvement is likely the synergistic result of several factors. It is unlikely that a single factor or a dietary supplement will be able to reproduce the results generated by an overall dietary change.

Though the FFQ used in this study has not been validated rigorously, a comparison to 7-day semi-quantitative dietary intake of people following the same Hallelujah Diet (unpublished data) showed that, on an energy basis, the only significant differences between nutrient intakes reported here and in that survey were for fiber and vitamin A. So, it appears that the FFQ captured nutrient intakes satisfactorily.

Our study had several limitations. First, because all of the subjects did not currently meet the diagnosis criteria of FMS, the results cannot be compared directly with other studies. It's possible, but cannot be proven here, that greater improvement would have been seen with people who were experiencing more pain. It's also possible that subjects with less severe pain were able to improve quicker. Equal percentages of subjects with more than 11 painful tender points were found among responders and non-responders.
Second, as an unblinded observational study there was no direct comparison with a control group. Many historical controls were available and the natural, chronic course of FMS is well described. However, the results would certainly be stronger if an active control group was included. Another limitation was the size of the treatment group. Though the subjects here seemed to be representative of people with FMS, it is not certain that the same results would be seen in a large study. These results should be reproduced and extended in a larger, controlled trial.

\section{Conclusions}

In summary, a diet intervention using a mostly raw, pure vegetarian diet produced dramatic improvements in FMS symptoms. 19 of 30 participants responded very favorably to the intervention, seeing marked improvement in all FMS symptoms. This dietary intervention shows that many fibromyalgia subjects can be helped even without understanding the full cause of their symptoms. Further controlled studies are needed to reproduce and extend the results obtained here to see if this dietary intervention is a viable adjunctive therapy for managing fibromyalgia in a clinical setting.

\section{Competing interests}

Michael Donaldson is a research scientist at the Hallelujah Acres Foundation, a foundation for investigations pertaining to the Hallelujah Diet. Funding for this study was provided by the Hallelujah Acres Foundation. Michael Donaldson is not a distributor of AIM products (Barleygreen and Herbal Fiberblend), nor does he have any financial interests in AIM, International.

Neal Speight has no competing interests, financial or otherwise. Stephen Loomis has no competing interests, financial or otherwise.

\section{Acknowledgments}

The author would like to give a special thanks to Mr. Graham Stephens for initiating the conversation to begin this study. A special thanks also to AIM International for donating all the Herbal Fiberblend and Barleygreen used in this study.

\section{References}

I. Goldenberg DL: Fibromyalgia, chronic fatigue syndrome, and myofascial pain syndrome. Curr Opin Rheumatol 1997, 9:135-143

2. Wallace DJ: The fibromyalgia syndrome. Ann Med 1997, 29:9-2I

3. Wolfe F, Anderson J, Harkness D, Bennett RM, Caro XJ, Goldenberg $\mathrm{DL}$, Russell IJ, Yunus $M B$ : Health status and disease severity in fibromyalgia: results of a six-center longitudinal study. Arthritis Rheum 1997, 40:1571-1579

4. Wolfe F, Ross K, Anderson J, Russell IJ, Hebert L: The prevalence and characteristics of fibromyalgia in the general population. Arthritis Rheum 1995, 38:19-28

5. White KP, Speechley M, Harth M, Ostbye T: The London Fibromyalgia Epidemiology Study: the prevalence of fibromyalgia syndrome in London, Ontario. J Rheumatol 1999, 26: I570-I 576

6. Hawley DJ, Wolfe F: Pain, disability, and pain/disability relationships in seven rheumatic disorders: a study of 1,522 patients. J Rheumatol 1991, I8:I552-1557 
7. Strombeck B, Ekdahl C, Manthorpe R, Wikstrom I, Jacobsson L: Health-related quality of life in primary Sjogren's syndrome, rheumatoid arthritis and fibromyalgia compared to normal population data using SF-36. Scand J Rheumatol 2000, 29:20-28

8. Kennedy M, Felson DT: A prospective long-term study of fibromyalgia syndrome. Arthritis Rheum 1996, 39:682-685

9. Wolfe F, Anderson J, Harkness D, Bennett RM, Caro XJ, Goldenberg DL, Russell IJ, Yunus MB: A prospective, longitudinal, multicenter study of service utilization and costs in fibromyalgia. Arthritis Rheum 1997, 40: 1560-1570

10. Alarcon GS, Bradley LA: Advances in the treatment of fibromyalgia: current status and future directions. Am J Med Sci 1998, 3 15:397-404

II. Goldenberg DL: Fibromyalgia syndrome a decade later: what have we learned? Arch Intern Med 1999, 159:777-785

12. Rossy LA, Buckelew SP, Dorr N, Hagglund KJ, Thayer JF, Mclntosh MJ, Hewett JE, Johnson JC: A meta-analysis of fibromyalgia treatment interventions. Ann Behav Med 1999, $21:|80-19|$

13. Pioro-Boisset M, Esdaile JM, Fitzcharles MA: Alternative medicine use in fibromyalgia syndrome. Arthritis Care Res 1996, 9:13-17

14. Hostmark AT, Lystad E, Vellar OD, Hovi K, Berg JE: Reduced plasma fibrinogen, serum peroxides, lipids, and apolipoproteins after a 3-week vegetarian diet. Plant Foods Hum Nutr 1993, 43:5561

15. Kaartinen K, Lammi K, Hypen M, Nenonen M, Hanninen O, Rauma $A L$ : Vegan diet alleviates fibromyalgia symptoms. Scand J Rheumatol 2000, 29:308-313

16. Mannerkorpi K, Burckhardt CS, Bjelle A: Physical performance characteristics of women with fibromyalgia. Arthritis Care Res 1994, 7:123-129

17. Burckhardt CS, dark SR, Bennett RM: The fibromyalgia impact questionnaire: development and validation. J Rheumatol I991, I 8:728-733

18. Ware JE Jr, Sherboume CD: The MOS 36-item short-form health survey (SF-36). I. Conceptual framework and item selection. Med Care 1992, 30:473-483

19. Flanagan JC: Measurement of quality of life: current state of the art. Arch Phys Med Rehabil 1982, 63:56-59

20. Ware JE, Snow KK, Kosinski M, Gandek B: SF-36 health survey manual \& interpretation guide. Boston: The Health Institute, New England Medical Center; 1993

2I. Bennett RM, Burckhardt CS, dark SR, O'Reilly CA, Wiens AN, Campbell SM: Group treatment of fibromyalgia: a 6 month outpatient program. I Rheumatol 1996, 23:52 I-528

22. Gowans SE, deHueck $A$, Voss $S$, Richardson M: A randomized, controlled trial of exercise and education for individuals with fibromyalgia. Arthritis Care Res 1999, I 2:120-128

Publish with BioMed Central and every scientist can read your work free of charge

"BioMedcentral will be the most significant development for disseminating the results of biomedical research in our lifetime."

Paul Nurse, Director-General, Imperial Cancer Research Fund

Publish with BMC and your research papers will be:

- available free of charge to the entire biomedical community

- peer reviewed and published immediately upon acceptance

- cited in PubMed and archived on PubMed Central

- yours - you keep the copyright

Submit your manuscript here

http://www.biomedcentral.com/manuscript/
BioMedcentral.com editorial@biomedcentral.com 